\title{
O PAPEL DA ESCOLA NO CONFLITO LINGUAGEM E ESTRUTURAS SOCIAIS
}

\section{Dulce Cassol Tagliani}

\section{RESUMO}

Neste artigo, pretendemos estabelecer uma relação entre problemas que envolvem o ensino de língua materna no Brasil e aspectos discriminatórios relacionados às diferentes variedades lingüísticas que coabitam na sociedade. Discutimos, então, que a escola parece não considerar os diferentes usos da linguagem em diferentes contextos de interação e continua voltada para a fragmentação, compartimentação e descontextualização da linguagem e do conhecimento. Nesse sentido, numa sociedade onde as relações são bastante assimétricas, a escola se apresenta como uma instituição que mantém a distância entre dominados e dominadores, ocasionando o fracasso escolar de alunos cuja produção lingüística não é legitimada pela escola, em função da posição que ocupam na estrutura das relações de força simbólica que refletem as relações de forças materiais que estruturam a sociedade.

\section{INTRODUÇÃO}

Uma das grandes preocupações relacionadas ao contexto educacional brasileiro é o tratamento dispensado à língua materna no âmbito escolar. Teoricamente, a escola tem o papel fundamental de dar significado ao conhecimento que ali transita, mediante a contextualização e o incentivo ao raciocínio e à criticidade. Vivemos um novo paradigma social, em que a educação como instrumento de conformação ao mundo do trabalho se perde para dar lugar a uma educação voltada para o "desenvolvimento das competências básicas tanto para o exercício da cidadania quanto para o desempenho de atividades profissionais" (PCN, 1999, p.23). Nesse sentido, seria necessário garantir o desenvolvimento de tais capacidades para se evitar a manutenção das desigualdades, que se fazem cada vez maiores em função do sistema capitalista vigente.

No entanto, segundo Soares (1993), a escola não tem demonstrado competência suficiente para educar, principalmente, as camadas populares, o que gera 0 fracasso e legitima as desigualdades sociais. Vale destacar que as classes populares conquistaram o espaço escolar através da democratização do ensino, que tomou uma direção quantitativa no sentido de ampliar a oferta educacional, principalmente o número de escolas para essas classes populares.

Porém, considerando particularmente o ensino da língua materna e como se trabalha a questão da linguagem, percebemos que a escola é um instrumento de manutenção da marginalidade social, já que propõe o aprendizado do diale- 
to padrão das classes dominantes e, conseqüentemente, a sujeição dos dialetos não-padrão ao dialeto padrão.

Nesse sentido, cabe uma reflexão sobre o papel da linguagem no contexto escolar, visto que, como mecanismo simbólico - cultural, social, político - acaba servindo tanto para incluir quanto para excluir. E, numa sociedade onde as relações são bastante assimétricas, a escola desponta como uma instituição que perpetua o abismo entre dominados e dominadores.

\section{LINGUAGEM DA/NA ESCOLA}

Sabidamente, o trabalho com a linguagem na escola está voltado para a formação da competência comunicativa e/ou lingüística do aluno. Trabalha-se, basicamente, com um conjunto fechado de regras, com o objetivo de proporcionar ao aluno o domínio da variedade considerada padrão. O acesso a essa variedade de prestígio está associado a conteúdos também de prestígio. A língua padrão torna-se, assim, "um sistema associado a um patrimônio cultural apresentado como um 'corpus' definido de valores, fixados na tradição escrita" (Gnerre, 1994, p. 6).

Segundo o referido autor, a afirmação de uma variedade sobre outras está relacionada à sua associação com a escrita e seu uso na transmissão de informações de ordem política e cultural. A diferenciação lingüística está fortemente relacionada com aspectos políticos - "as línguas européias começaram a ser associadas à escrita dentro de restritos ambientes de poder: nas cortes de príncipes, bispos, reis e imperadores" (id, ibidem, p. 7).

A variedade lingüística usada em grupos de poder torna-se, então, central na identidade lingüística nacional, enquanto portadora de uma tradição e de uma cultura. Tal variedade acaba sendo legitimada, isto é, uma dada norma lingüística é aceita e reconhecida como "a língua".

A escola, segundo Soares (1993, p. 54), transforma a cultura e a linguagem dos grupos dominantes em "saber escolar legítimo" e impõe tal saber aos grupos dominados. A marginalização é perpetuada em vista dessa função de manutenção da estrutura social vigente e suas desigualdades e privilégios. Conseqüentemente, a escola exerce um poder de "violência simbólica", ou seja, legitima a cultura e a linguagem das classes dominantes (Bourdieu, 1996).

Dessa forma, a escola, principalmente por meio da linguagem, mantém a estabilidade de um sistema discriminatório de estratificação social. A discriminação das classes populares é explicada em função da nítida opressão exercida pelas classes dominantes, mediada pela escola, através da imposição de sua cultura e de sua linguagem, consideradas legítimas, em detrimento de uma cultura e linguagem consideradas "deficientes", pelo simples fato de serem diferentes daquela considerada legítima (Soares, 1993).

Um dos principais instrumentos de inculcação de diferenças é o livro didático, sendo considerado, por Faria (2005, p.13), como um dos "veículos utilizados 
pela escola para a transmissão da ideologia burguesa". Conforme estudos realizados pela autora, "o livro didático não vê o desenvolvimento do homem, da sociedade e o processo de trabalho dialeticamente relacionando o homem que produz sua existência e sendo determinado pelo que e pelo como a produziu" (id., p. 27). Dessa forma, apresenta uma visão considerada idealista, casuísti$\mathrm{ca}$, linear e genérica. Não há qualquer relação entre, por exemplo, o trabalho e a organização da sociedade. Conseqüentemente, não há referência a classes sociais, burguesia, proletariado, dono dos instrumentos de produção e dono e vendedor da força de trabalho: "todos trabalham! Aí está a ideologia dominante camuflando a realidade. A ênfase no indivíduo enquanto responsável pelo seu sucesso reforça essa dissimulação" (id., p.75). Dessa forma, o livro didático reproduz a classe operária, porém de posse da ideologia burguesa, sendo, assim, conformista e passiva.

Nesse sentido, as manifestações ideológicas da classe dominante são transmitidas de forma universal - para todos e sempre. As relações humanas são coisificadas na medida em que a ideologia burguesa justifica e mantém a realidade, reproduzindo-a. Nesse sentido, o discurso da escola não está desligado da realidade, visto que ela ignora os interesses das classes populares, servindo à manutenção dos interesses da classe dominante (Faria, 2005).

$\mathrm{Na}$ escola, professores e alunos interagem lingüisticamente em condições sociais concretas que, segundo Bourdieu (1996, p. 32), funciona como um mercado lingüístico onde se constrói a legitimação da língua oficial, que, sendo obrigatória em espaços oficiais, como a escola, "torna-se a norma teórica pela qual todas as práticas lingüísticas são objetivamente medidas".

Ainda conforme Bourdieu (1996), na comunicação pedagógica, cabe ao professor referir sempre a cultura e a linguagem legítimas. No entanto, essa comunicação está fundamentada em bases desiguais, visto que os alunos das classes dominantes chegam à escola em condições de usar o 'capital cultural' e o 'capital lingüístico escolarmente rentável', já que estão familiarizados com eles em seu grupo social. Já os alunos das classes populares fracassam ao chegarem à escola, em função de sua linguagem ser considerada não reconhecida socialmente. $\mathrm{O}$ fato de não dominarem a linguagem da escola reflete na incapacidade de compreensão e expressão na comunicação pedagógica. Nesse sentido, a escola contribui de forma direta para a desvalorização dos modos de expressão populares e para o reconhecimento da língua legítima.

\section{A LINGUAGEM COMO BEM SIMBÓLICO}

No universo social, além de bens materiais, como a força de trabalho, mercadorias e serviços, circulam bens simbólicos, entre eles a linguagem. Num evento de comunicação lingüística se estabelece uma relação de "força simbólica" determinada pela estrutura do grupo social em que ocorre a comunicação relações entre os interlocutores. Segundo Bourdieu (1996), as relações de força lingüísticas justificam o exercício de poder e dominação de certos falantes sobre outros, além de explicar a valorização de determinados produtos lingüísticos. 
Numa situação de interação verbal - mercado lingüístico - o que se considera é a natureza das relações sociais existentes entre os interlocutores, isto é, situação econômica, prestígio profissional, entre outros. Nesse sentido, as relações de forças simbólicas presentes na comunicação lingüística "definem quem pode falar, a quem, e como; atribuem valor e poder à linguagem de uns e desprestígio à linguagem de outros; impõem o silêncio a uns e o papel de portavoz a outros" (Soares, 1993, p. 56).

Segundo Bourdieu (1996), é a análise da economia das trocas lingüísticas fenômenos relacionados à produção, distribuição e consumo da linguagem que explica os problemas ocorridos em situações de interação verbal, incluindo a situação escolar. Em certas situações lingüísticas, observa-se que determinadas pessoas falam ou escrevem e são respeitadas em função de sua linguagem estar autorizada, legitimada, reconhecida. Por outro lado, se um outro falante estiver em situação hierarquicamente inferior, seu discurso não terá o mesmo crédito, em função do não reconhecimento de sua variedade lingüística. Segundo o autor, em meio à luta para a imposição da visão legítima, os agentes detêm um poder proporcional a seu capital simbólico.

Nesse sentido, Soares (1996, p. 57), recuperando Bourdieu, afirma que

o valor social dos produtos lingüísticos é-lhes atribuído em função de sua relação com um determinado mercado lingüístico, que estabelece diferenças entre esses produtos, fazendo com que alguns, e não outros, rendam lucro ou proveito para o falante, não por suas qualidades intrínsecas, mas pela relação entre o sistema de diferenças lingüísticas e o sistema de diferenças sociais. As características lingüísticas que correspondem às posições econômicas e sociais privilegiadas ganham legitimidade, e assim se desenvolve o reconhecimento de uma linguagem legítima, que se converte em capital lingüístico, permitindo a obtenção de lucro por aqueles que o detêm.

Como as relações de força lingüísticas estão presentes na sociedade e, conseqüentemente, na escola - onde agem de forma intensa - justifica-se o fracasso escolar de alunos cuja produção lingüística não é legitimada pela escola em função da posição que ocupam na estrutura das relações de força simbólica que refletem as relações de força materiais que estruturam a sociedade (Soares, 1993).

A perspectiva de Bourdieu sobre a economia das trocas lingüísticas favorece a compreensão dos problemas de linguagem que ocorrem no processo de escolarização, em função de ter deslocado o ângulo de análise da caracterização da linguagem para a caracterização das condições sociais onde ocorre - estrutura social. Desse modo, na interação pela linguagem estão em primeiro plano os lugares sociais e os papéis ocupados pelos indivíduos na interação.

\section{ESCOLA E SOCIEDADE}

Segundo Faria (2005, p. 11), "educar é transmitir idéias e conhecimentos que através de uma prática podem transformar ou conservar a realidade". Nesse sentido, pensando no papel que a escola desempenha, resgatamos alguns 
questionamentos apresentados pelo autor, por julgarmos importantes na reflexão que desenvolvemos: como a escola pode atuar para a transformação da sociedade? A escola poderia ser diferente do que é, principalmente em relação às classes populares?

Numa sociedade capitalista, onde a divisão do trabalho implica a divisão da sociedade em classes, é importante frisar que a escola não contribui de maneira efetiva na educação do proletariado, visto que apenas reproduz a sociedade burguesa, "através da inculcação da sua ideologia e do credenciamento, que permite a hierarquia na produção, o que garante maior controle do processo pela classe dominante" (Faria, 2005, p. 12).

Além disso, o processo de socialização realiza-se no contexto de uma estrutura social específica, estando relacionada com a distribuição de conhecimento. Nesse sentido, para fazer parte de um grupo é preciso que cada indivíduo sacrifique especificidades de seus desejos e objetivos. Assim, todo lugar social compromete a individualidade social e determina como a pessoa interage, sem considerar as características empíricas do sujeito (Berger; Luckmann, 1985).

A escola, então, nada pode fazer contra as desigualdades, visto que é modelada pelas relações econômicas e sociais de tal sociedade. A impotência da escola perdurará enquanto a estrutura de discriminações geradas fora dela continuar existindo e enquanto for, erroneamente, vista como espaço de neutralidade, de onde estariam ausentes os antagonismos e as contradições de uma sociedade classista.

O que podemos observar no sistema educacional brasileiro é, antes de tudo, uma escola que se volta 'contra' o povo, visto que a relação entre origem social e fracasso é evidente: as classes socioeconomicamente desfavorecidas são as que mais fracassam na escola. $O$ aluno da classe dominada encontra na escola modelos ou padrões que não são os seus, e seu comportamento passa a ser avaliado em função desse modelo - "os testes e provas a que é submetido são culturalmente preconceituosos, construídos a partir de pressupostos etnocêntricos, que supõem familiaridade com conceitos e informações próprios do universo cultural das classes dominantes - processo de marginalização cultural" (Soares, 1993, p. 15).

Nesse contexto, o papel da linguagem desponta como fundamental, visto que é, ao mesmo tempo, o principal produto da cultura e o principal instrumento para sua transmissão. Assim, o confronto entre as culturas é, basicamente, um confronto entre os usos da língua numa ou noutra cultura.

Desse modo, a escola parece ser um espaço necessário e fundamental para que as classes dominadas reajam ao domínio elitista. Para isso, necessita de professores capacitados e conscientes de seu papel, que vejam na educação e na escola um ambiente para a formação de seres pensantes e críticos e não apenas um espaço para a transmissão e manutenção de ideologias dominantes. A hegemonia vigente no sistema educacional brasileiro constitui-se num entrave para o desenvolvimento de uma sociedade voltada, verdadeiramente, 
para a formação de cidadãos que possam participar mais ativamente do seu contexto social.

\section{CONSIDERAÇÕES FINAIS}

A visível crise por que passa o ensino de língua materna é considerada por muitos como tendo origem nas desigualdades sociais e, conseqüentemente, nos diferentes usos da linguagem.

A democratização do ensino foi uma resposta do Estado às reivindicações das camadas populares da sociedade, porém continuou a privilegiar a cultura e a linguagem das classes favorecidas, em função de a escola, historicamente, ser destinada a essas classes. Não houve reestruturação em termos de objetivos e organização, o que justifica a crise da linguagem em conjunto com a crise da escola.

O grande problema é solucionar o conflito lingüístico e social existente no contexto escolar. Sabemos que para se adaptar às exigências de uma sociedade cada vez mais globalizada, o indivíduo precisa, necessariamente, adquirir a linguagem socialmente prestigiada, a despeito de ficar relegado à marginalidade social. No entanto, práticas de substituição dialetal não são suficientes para desfazer esse conflito, visto que o contato das classes populares com a variedade padrão fica restrito ao contexto escolar, e da forma mais arcaica possível - reprodução de nomenclatura e estruturas gramaticais que em nada colaboram para um efetivo uso da variedade padrão em situações comunicativas que assim a requerem.

\section{BIBLIOGRAFIA}

BERGER, P.; LUCKMANN, T. A construção social da realidade: tratado de sociologia do conhecimento. 23. ed. Petrópolis: Vozes, 1985.

BOURDIEU, P. A economia das trocas lingüísticas: o que falar quer dizer. São Paulo, Editora da USP, 1996.

BRASIL, Ministério da Educação, Secretaria de Educação Média e tecnológica. Parâmetros Curriculares Nacionais: ensino médio. Brasília: Ministério da Educação, 1999.

FARIA, A. L. Ideologia no livro didático. 15. ed. São Paulo: Cortez, 2005.

GNERRE, M. Linguagem, escrita e poder. São Paulo: Martins Fontes, 1994.

SOARES, M. Linguagem e escola: uma perspectiva social. São Paulo: Ática, 1993. 